\title{
LABORATORY RISK INDICATOR FOR NECROTIZING FASCIITIS (LRINEC) SCORE FOR THE ASSESSMENT OF NECROTIZING FASCIITIS IN HIMALAYAN REGION.
}

\author{
Dr. Jeevan Kumar', Dr. Ramesh Bharti², Dr. Amar Verma ${ }^{3}$, Dr. Rajesh Sharma ${ }^{4}$ \\ ${ }^{1}$ MS, Department of General Surgery, Dr. Rajendra Prasad Govt. Medical College \& Hospital,
} Kangra, Tanda, H.P. India

${ }^{2}$ Professor, Department of General Surgery, Dr. Rajendra Prasad Govt. Medical College \& Hospital, Kangra, Tanda, H.P. India

${ }^{3}$ Associate Professor, Department of General Surgery, Dr. Rajendra Prasad Govt. Medical College \& Hospital, Kangra, Tanda, H.P. India

${ }^{4}$ Assistant Professor, Department of General Surgery, Dr. Rajendra Prasad Govt. Medical College \& Hospital, Kangra, Tanda, H.P. India

Article Info: Received 17 August 2021; Accepted 29 September 2021

DOI: https://doi.org/10.32553/ijmbs.v5i10.2209

Corresponding author: Dr. Jeevan Kumar

Conflict of interest: No conflict of interest.

\begin{abstract}
Background: The LRINEC score (laboratory risk indicators for necrotizing fasciitis) was established in 2004 to aid in the differentiation of necrotizing fasciitis from severe soft tissue infections.

Methods: The study included all patients hospitalized to the department of general surgery at Dr. Rajendra Prasad Govt. Medical College \& Hospital, Kangra, Tanda, H.P. India with a diagnosis of necrotizing fasciitis for a period of one year, from June 2018 to May 2019. At the time of admission, the patient's hemoglobin, white blood cell count, C-reactive protein, blood glucose level, urea, sodium, potassium and creatinine levels (LIRNEC Score) were calculated.

Results: In all the patients LRINEC Score was $>6$. Out of 60 patients, $14(23 \%)$ patients had LRINEC Score in between 6 to 7 and $46(76 \%)$ patients had LRINEC score $>8$.

Conclusion: The LRINEC score of 6 and above suggest NF and therefore aiding in the early recognition of NSTI and its management.
\end{abstract}

\section{Introduction}

Necrotizing fasciitis (NF) is a severe and sometimes fatal soft tissue infection that spreads quickly along fascial planes. This fast spread frequently results in hemodynamic instability and systemic sepsis, which can progress to multiple organ failure and death. Due to the severity of this illness, it is critical to obtain prompt diagnosis and treatment, including surgical debridement. Necrotizing fasciitis should be handled with a high index of suspicion because of the severity of the effects of delayed therapy. Unfortunately, the frequent presenting symptoms of swelling, pain, and erythema [1] are non-specific, and early necrotizing fasciitis can easily be confused with cellulitis [2], which is generally managed non-operatively. There are more specific "hard symptoms" of necrotizing fasciitis, including exaggerated pain, quickly spreading infection, bullae, skin ecchymosis/sloughing, gas in tissue, skin anaesthesia, edoema other than erythema, and sepsis, however they are present in only $43 \%$ of cases [3].

Numerous additional tests, including advanced imaging, tissue oxygen monitoring, the finger test and early histological analysis have been reported to aid in the diagnosis of this difficult clinical situation $[4,5]$. Another tool to help in diagnosing necrotizing fasciitis is the laboratory risk indicators (LRINEC score). Wong et al. developed this test in 2004 as a diagnostic tool that utilizes routine laboratory tests to differentiate necrotizing fasciitis from other severe soft tissue infections [6]. The LRINEC score is a weighted score from $0-13$, using C-reactive protein, glucose, sodium, white blood cell count, hemoglobin and creatinine. The 
purpose of this study is to evaluate the LRINEC score in NF patients in Himalayan region.

\section{Material and Method}

The approval from the institutional scientific review protocol committee and the ethical committee was taken. Additionally, written informed consent was obtained from the patient. The study included all patients hospitalized to the department of general surgery at Dr. Rajendra Prasad Govt. Medical College \& Hospital, Kangra, Tanda, H.P. India with a diagnosis of necrotizing fasciitis for a period of one year, from June 2018 to May 2019.

At the time of admission, the patient's hemoglobin, white blood cell count, C-reactive protein, blood glucose level, urea, sodium, potassium and creatinine levels (LIRNEC Score) were calculated. LRINEC score more than 6 was taken as diagnostic for necrotizing fasciitis.

\section{Results}

\section{Laboratory risk indicator for necrotizing soft tissue infection}

54 (90\%) patients had CRP levels of more than 150 mg/dl. $6(10 \%)$ patients had CRP levels less than 150 $\mathrm{mg} / \mathrm{dl}$. WBC count was $<15,000$ cells $/ \mathrm{mm} 3$ in 32 $(53.3 \%),>15,000$ in $18(30 \%)$ and $>25,000$ in 10 $(16.7 \%)$ of patients. $41(68.3 \%)$ of cases had haemoglobin levels of less than $11 \mathrm{~g} / \mathrm{dl} .16(26.7 \%)$, $3(5 \%)$ patients had $\mathrm{Hb}$ level $11-13.5 \mathrm{~g} / \mathrm{dl}$ and $>13.5 \mathrm{~g} / \mathrm{dl}$ respectively. Sodium levels were $>135$ and $<135 \mathrm{mmol} / 1$ in $14(23.3 \%)$ and $46(76.7 \%)$ of cases respectively. 32 $(53.3 \%)$ patients had creatinine levels less than 1.6 $\mathrm{mg} / \mathrm{dl} .17$ (28.3\%) patients had glucose levels of more than $180 \mathrm{mg} / \mathrm{dl} .43(71.7 \%)$ patients had glucose levels less than $180 \mathrm{mg} / \mathrm{dl}$.

Table 1: Laboratory risk indicator for necrotizing soft tissue infection $(n=60)$

\begin{tabular}{|c|c|c|c|}
\hline Indicators & & Total no of patients & Percentage \\
\hline \multirow[t]{2}{*}{ C-Reactive proteins } & $<150 \mathrm{mg} / \mathrm{dl}$ & 6 & 10 \\
\hline & $>150 \mathrm{mg} / \mathrm{dl}$ & 54 & 90 \\
\hline \multirow[t]{3}{*}{ WBC Count (cells $/ \mathrm{mm}^{3}$ ) } & $<15,000$ & 32 & 53.3 \\
\hline & $>15,000$ & 18 & 30 \\
\hline & $>25,000$ & 10 & 16.7 \\
\hline \multirow[t]{3}{*}{ Haemoglobin level $(\mathrm{g} / \mathrm{dl})$} & $>13.5$ & 3 & 5 \\
\hline & $11-13.5$ & 16 & 26.7 \\
\hline & $<11$ & 41 & 68.3 \\
\hline \multirow[t]{2}{*}{ Sodium level (mmol/l) } & $>135$ & 14 & 23.3 \\
\hline & $<135$ & 46 & 76.7 \\
\hline \multirow[t]{2}{*}{ Creatinine level (mg/dl) } & $<1.6$ & 32 & 53.3 \\
\hline & $>1.6$ & 28 & 46.7 \\
\hline \multirow[t]{2}{*}{ Glucose level (mg/dl) } & $<180$ & 43 & 71.7 \\
\hline & $>180$ & 17 & 28.3 \\
\hline
\end{tabular}

$(\mathrm{n}=$ total patient in the study)

\section{Lrinec Score}

In all the patients LRINEC Score was $>6$. Out of 60 patients, 14(23\%) patients had LRINEC Score in between 6 to 7 and $46(76 \%)$ patients had LRINEC score $>8$.

Table 2: LRINEC Score $(n=60)$

\begin{tabular}{|l|l|l|}
\hline LRINEC Score & Total no of patients & Percentage \\
\hline$<5$ & 0 & 0 \\
\hline $6-7$ & 14 & 23 \\
\hline$>8$ & 46 & 76 \\
\hline
\end{tabular}

$(\mathrm{n}=$ total patient in the study)

\section{Discussion}

$\mathrm{NF}$ is important surgical urgency with a high mortality rate, even with sufficient treatment, with the reported rate of mortality varying from $6 \%$ to $36 \%$. Clinical scores like the LRINEC are available to help diagnose
$\mathrm{NF}$ and differentiate it from other skin and soft tissue infections. The study by Wong $\mathrm{CH}$ et al indicated that LRINEC is an effective tool for early detection of NF and score of 6 and above suggest NF [6]. Watson et al carried out a review study in 33 patients of NSTI. $60 \%$ had a LRINEC score $>6$ and $40 \%$ had a score of $<6$ 
[7]. In our study, all the patients had LRINEC score of more than 6 with a maximum score of 13 . The mean LRINEC score in our study was 8.38. LRINEC score predicts the presence of NSTI based on the severity of sepsis and ultimately aiding in the early recognition of NSTI and its management.

\section{Conclusion}

LRINEC score is a powerful tool to help differentiate it from other skin and soft tissue infections. In our study, all the patients had LRINEC score of more than 6 with a maximum score of 13. The score of 6 and above suggest NF with the possible addition of clinical perimeters such as pain, pyrexia and comorbidities. It can be an adjunct to a clinical diagnosis.

\section{References}

1. Goh $\mathrm{T}$, Goh LG, Ang $\mathrm{CH}$, Wong $\mathrm{CH}$. Early diagnosis of necrotizing fasciitis. Br J Surg. 2014;101(1):e119-25.
2. Shiroff AM, Herlitz GN, Gracias VH. Necrotizing soft tissue infections. J Intensive Care Med. 2014;29(3):138-44.

3. Schuster L, Nuñez DE. Using clinical pathways to aid in the diagnosis of necrotizing soft tissue infections synthesis of evidence. Worldviews Evid Based Nurs. 2012;9(2):88-99.

4. Wong $\mathrm{CH}$, Wang YS. The diagnosis of necrotizing fasciitis. Curr Opin Infect Dis. 2005;18(2):101-6.

5. Wang TL, Hung CR. Role of tissue oxygen saturation monitoring in diagnosing necrotizing fasciitis of the lower limbs. Ann Emerg Med. 2004;44(3):222-8.

6. Wong $\mathrm{CH}$, Khin LW, Heng KS, Tan KC, Low CO. The LRINEC (Laboratory Risk Indicator for Necrotizing Fasciitis) score: a tool for distinguishing necrotizing fasciitis from other soft tissue infections. Crit Care Med. 2004;32(7):1535-41.

7. Watson H, Hassan S, Davies M. Outcomes following necrotizing fasciitis: an 8-year review. Res J Infect Dis. 2014;2:2-5. 